\title{
Expressed emotion - a determinant of relapse in schizophrenia: a case report and literature review
}

\author{
Arpita Goswami Banerjee* and Carolina Retamero \\ *Correspondence: goswamia@einstein.edu

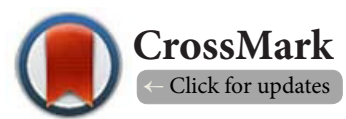

Department of Psychiatry and Behavioral Science, Einstein Medical Center, Philadelphia, PA, USA.

\begin{abstract}
Expressed emotion (EE) pertains to care giver's attitude towards a person with a mental disorder. It is a characteristic of the family milieu that has been found to be one of the major psychosocial stressors and an important predictor of symptom relapse in a wide range of psychiatric disorders. Research on EE was initiated early in the 1950s, and the researchers observed that close emotional ties between families could lead to minimum stimulation and social withdrawal by a patient suffering from schizophrenia. They also observed that such patients were more likely to relapse when living with close relatives who had negative attitudes. The communication patterns in families with high EE relatives are usually characterized by intense and confronting verbal exchanges. The authors present the case of a young African American male with acute relapse of symptoms of schizophrenia in the background of a family with high EE.
\end{abstract}

Keywords: Expressed emotion, schizophrenia, psychiatric disorders, relapse

\section{Introduction}

Schizophrenia is a chronic, severe and disabling mental disorder characterized by deficits in thought processes, perceptions, and emotional responsiveness. It affects around 2.5 million people in the United States [1] and it is commonly associated with impairments in social and occupational functioning [2]. It has a devastating effect on family, society, workforce and the economy, with a total economic burden of $\$ 62.7$ billion [3].

Expressed emotion (EE) refers to the quality of the emotional climate between a relative and a family member with a serious psychiatric disorder [4]. It is a significant characteristic of the family milieu that has been found to predict symptom relapse in a wide range of mental disorders. High EE is a predictor of relapse in many psychiatric illnesses [5], such as schizophrenia [6], depressive disorders [7], acute mania [8], and alcoholism [9]. High EE families are those who endorse high levels of criticism, hostility, or emotional over involvement [10]. They report higher levels of disturbed behavior, subjective burden and perceive lower coping skills. In contrast, low EE families are more knowledgeable, perceive better coping skills and report a low subjective burden, personal stress, behavioral disturbance. [11].

EE in schizophrenia has the strongest EE-relapse relationship, and it's considered a cogent predictor for relapse [10]. The mean relapse rate is $48 \%$ for patients living with high EE families versus $21 \%$ for those living low EE families [12].

Despite the available literature highlighting the importance of EE in schizophrenia, EE is not commonly discussed in clinical practice and it gets lost in the treatment of the patient's visible clinical symptoms. The authors present the case of a young African-American man with history of schizophrenia who relapsed in the context of a High EE family.

\section{Case presentation}

Mr. B, a 24 year old African American male, previously diagnosed with post-traumatic stress disorder, paranoid schizophrenia and HIV, presented after allegedly holding a knife at his mother and delusions that he did not know his mother or his brothers. His family reported that after he stopped his psychiatric medications a few weeks before presentation, he had been paranoid, aggressive, sleeping poorly, seclusive to his room, threatening to kill family members, and exhibiting frequent crying spells.

Mr. B's denied using any drugs or alcohol and his urine drug screen was negative. His family history was significant for his mother abusing unknown substances. He was the youngest of 8 siblings; his mother had abandoned him and he was raised by his step father until the age of 6 years, at which time, his mother resumed his care. He was verbally abused by his mother and physically abused by his brothers. At the time of admission 
Banerjee et al. Journal of Psychiatry and Brain Functions 2014,

Mr. B was living with his mother and two brothers.

Physical examination was remarkable for poor nutrition and low body mass index (16.6). His Mini-mental status examination score was $27 / 30$. Laboratory tests on admission revealed mild increase in transaminases, mild anemia and leucopenia (hemoglobin 12.4, white blood cell count: 3.7). Thyroid and lipid profiles were within normal limits. CD4 count was 22. Serologies for sexually transmitted diseases were negative. Infectious disease consult team started prophylaxis treatment for Pneumocystis pneumonia.

Following admission Mr. B continued to be withdrawn with psychomotor retardation, severe paranoia and was observed to be responding to internal stimuli. He was tangential and appeared religiously preoccupied about the difference of faith between him and his mother. He was seclusive, guarded, with no interaction with staff and peers. After several days of pharmacotherapy with an antipsychotic and an antidepressant he started to show clinical improvement. He became more social and started attending groups and therapy. He endorsed improved mood symptoms and regained weight. His discharge labs showed improved results with hemoglobin 14.6, CD4 count 220 and normal transaminases. His body mass index improved to 18.7 and his Mini-mental status scored 28/30 at the time of discharge.

Mr. B disclosed his mother being critical and verbally abusive towards him since his childhood and that she had been giving him diazepam as she believed that he had an anxiety disorder. He reported feeling anxious with her hostile behavior and refused to return to his mother on discharge. Mr. B's mother's hospital visit was remarkable for hostility towards the staff, physicians and social workers. She was overtly critical about her son's behavior, accusing him of being lazy, selfish and avoiding household responsibilities. She demanded to take Mr. B home, stating that he needed treatment for anxiety with benzodiazepines, and not schizophrenia. Her hostility towards her son was clearly evident from the verbal altercations she had with her son during her few initial visits to the hospital, which required staff intervention. Her over invlovement in her son's life was demonstrated by her multiple daily phone calls to the hospital and social worker demanding updates on her son's progress.

Medical records indicated that Mr. B's mother had exhibited similar behaviors to the treatment teams in the past and that his prior hospital admissions were under similar circumstances (disruptive home environment). Mr. B refused to meet his mother or have a family meeting during the hospital stay. He expressed wish to be discharged to a more structured residential environment as going home would be a detriment to his recovery. He was discharged to an inpatient rehabilitation program with psychiatric and medical follow up appointments.

A 3 month and a 6 month follow up of Mr. B's progress by telephone revealed that $\mathrm{Mr}$. B was engaged in vocational rehabilitation and was doing well in terms of his mental illness and HIV treatment adherence.

\section{Discussion}

This case highlights the potential clinical association between EE and relapse of schizophrenia. Although there are several contributing factors in Mr. B's relapse, including non-adherence to medications, PTSD, HIV infection, abandonment issues and physical abuse, we believe the high level of EE in the family, manifested by hostile family environment, maternal criticism and verbal and emotional abuse, was pivotal in his frequent relapses and hospitalizations.

Being critical is one of the essential components of expressed emotion. Caregivers who are critical of the patient are more likely to hold the patient responsible for their actions, rather than as an effect of the illness [13]. In this case, the lack of understanding of mental illness played an additional role in the patient's decompensation. Mr. B's mother frequent verbal abuse and derogatory remarks toward Mr. B were most likely secondary to her limited knowledge about schizophrenia and her inability to recognize its negative symptoms including lack of emotional responsiveness, motivation, socialization, speech, and movement. Criticism directed by caregivers towards a family member with schizophrenia, both from the perspective of the patient and of the caregiver, predicts relapse [14].

Although the impact of EE is well established, there are some cultural differences. Comparative studies in the United States between Caucasian and African American families showed that high emotional over involvement predicted increased likelihood of relapse at 1-year follow-up in both groups [15]. Caucasian family members felt more subjectively burdened and had more rejecting attitudes towards their relatives with schizophrenia than African American families. They also tended to be less tolerant of loss of a productive contributory role by the relative. However, African American families seemed to be less tolerant of disruptive psychotic behaviors when compared with Caucasian families $[16,17]$ which could result in multiple hospitalizations. Families of Caucasians patients suffering from schizophrenia exhibited higher $\mathrm{EE}$ and relapse rates when compared to family members of Mexican schizophrenic patients [18].

A 20 year prospective study of EE in schizophrenia revealed that the level of EE in the family and its components including hostility, emotional over-involvement, and critical comments, are related to treatment outcomes in schizophrenia [19]. A high level of criticism and hostility is associated with a higher number of relapses and amplification of the positive symptoms in both, the short-term and long-term course of the illness. Robust assessment of psychosocial factors and interventions specifically focused on family psycho-education could play a pivotal role in reducing high $\mathrm{EE}$ and relapse of symptoms and facilitate a comprehensive care in patients with schizophrenia. The inclusion of educational sessions to caregivers about the etiology, symptoms, and management of schizophrenia, the use of medications, and family intervention programs focused on stress reduction, would enhance families' coping skills 
and lessens their tendency to be critical [20] and contribute to reduced relapse and hospitalizations in patients with $\mathrm{EE}$ families [21].

Some limitations of our report include that no objective measurement of EE was used. The diagnosis of EE was based on the subjective statements made by Mr. B's mother and observations of her interactions with her son and the treatment team, rather than utilizing EE assessment tools (Camberwell family interview, Five-minute speech sample, Level of EE, Perceived criticism). In addition, due to the extreme resistance expressed by Mr. B's mother towards the treatment team, educational sessions were unsuccessful. After facing these circumstances the treatment team proceeded to discharge Mr. B to a less hostile and more structured residential facility. Further research is needed and should be directed to clarify the true etiological, responsive and biologic role of EE in patients with schizophrenia, and to determine the different forms of family interventions which would be essential in reducing EE among primary caregivers.

\section{Conclusion}

EE is not commonly discussed in clinical practice and it gets lost in the treatment of the patient's visible clinical symptoms. Clinicians need to be aware of the existence of $E E$ in the treatment of patients with schizophrenia and address it early to optimize benefits for the patients and their caregivers. A focused, multidisciplinary, bio-psychosocial approach involving the patient, his family and caregivers, and the treatment team members including social worker, case manager, family therapist, occupational therapist, community support team, primary care physician and psychiatrist is imperative. Interventions should be aimed to address vulnerable factors such as stressful life events, emotional, physical, social and financial burden of the caregivers, and protective factors such as educational sessions to increase awareness about symptoms of schizophrenia and low EE of caregivers.

\section{Competing interests}

The authors declare that they have no competing interests.

Authors' contributions

\begin{tabular}{|l|c|c|}
\hline Authors' contributions & AG & CR \\
\hline Research concept and design & $\checkmark$ & $\checkmark$ \\
\hline Collection and/or assembly of data & $\checkmark$ & $\checkmark$ \\
\hline Data analysis and interpretation & $\checkmark$ & $\checkmark$ \\
\hline Writing the article & $\checkmark$ & $\checkmark$ \\
\hline Critical revision of the article & $\checkmark$ & $\checkmark$ \\
\hline Final approval of article & $\checkmark$ & $\checkmark$ \\
\hline
\end{tabular}

\section{Publication history}

Senior Editor: Gianluca Serafini, Sapienza University of Rome, Italy. Received: 24-Apr-2014 Final Revised: 12-Aug-2014

Accepted: 21-Aug-2014 Published: 03-Sep-2014

\section{References}

1. National Institute of Mental Health, Schizophrenia. | Website

2. American Psychiatric Association. Diagnostic and Statistical Manual of Mental Disorders, Fifth Edition (DSM-5). I Book

3. Wu EQ, Birnbaum HG, Shi L, Ball DE, Kessler RC, Moulis M and Aggarwal J. The economic burden of schizophrenia in the United States in 2002. J Clin Psychiatry. 2005; 66:1122-9. | Article | PubMed

4. Wearden AJ, Tarrier N, Barrowclough C, Zastowny TR and Rahill AA. A review of expressed emotion research in health care. Clin Psychol Rev. 2000; 20:633-66. | Article | PubMed

5. Brown GW, Birley JL and Wing JK. Influence of family life on the course of schizophrenic disorders: a replication. Br J Psychiatry. 1972; 121:24158. | Article | PubMed

6. Kavanagh DJ. Recent developments in expressed emotion and schizophrenia. Br J Psychiatry. 1992; 160:601-620. | Article

7. Hooley JM and Teasdale JD. Predictors of relapse in unipolar depressives: expressed emotion, marital distress, and perceived criticism. J Abnorm Psychol. 1989; 98:229-35. | Article | PubMed

8. Micklowitz DJ and Goldstein MJ. Bipolar Disorder: A Family-Focused Treatment Approach. New York, Guilford, 1997.

9. O'Farrell TJ, Hooley J, Fals-Stewart W and Cutter HS. Expressed emotion and relapse in alcoholic patients. J Consult Clin Psychol. 1998; 66:744-52. | Article | PubMed

10. Butzlaff RL and Hooley JM. Expressed emotion and psychiatric relapse: a meta-analysis. Arch Gen Psychiatry. 1998; 55:547-52. | Article | PubMed

11. Dinesh Bhugra and Kwame McKenzie. Expressed emotion across cultures. Advances in Psychiatric Treatment. 2003; 9:342-348. | Article

12. Kavanagh DJ. Recent developments in expressed emotion and schizophrenia. Br J Psychiatry. 1992; 160:601-20. | PubMed

13. Barrowclough $C$ and Hooley JM. Attributions and expressed emotion: a review. Clin Psychol Rev. 2003; 23:849-80. | Article | PubMed

14. Medina-Pradas C, Navarro JB, Pousa E, Montero MI and Obiols JE. Expressed and perceived criticism, family warmth, and symptoms in schizophrenia. Span J Psychol. 2013; 16:E45. | Article | PubMed

15. Swaran P. Singh, Kath Harley, and Kausar Suhail. Cultural Specificity of Emotional Overinvolvement: A Systematic Review. Schizophrenia Bulletin. 2013; 39:449-463. | Article

16. Rosenfarb IS, Bellack AS and Aziz N. A sociocultural stress, appraisal, and coping model of subjective burden and family attitudes toward patients with schizophrenia. J Abnorm Psychol. 2006; 115:157-65. | Article | PubMed

17. Johnson ED. Differences among families coping with serious mental illness: a qualitative analysis. Am J Orthopsychiatry. 2000; 70:126-34. | PubMed

18. Kopelowicz A, Zarate R, Gonzalez V, Lopez SR, Ortega P, Obregon N and Mintz J. Evaluation of expressed emotion in schizophrenia: a comparison of Caucasians and Mexican-Americans. Schizophr Res. 2002; 55:179-86. | Article | PubMed

19. Cechnicki A, Bielanska A, Hanuszkiewicz I and Daren A. The predictive validity of expressed emotions (EE) in schizophrenia. A 20-year prospective study. J Psychiatr Res. 2013; 47:208-14. | Article | PubMed

20. Hatfield $A B$, Spaniol $L$ and Zipple AM. Expressed emotion: a family perspective. Schizophr Bull. 1987; 13:221-6. | Article | PubMed

21. Dyck DG, Hendryx MS, Short RA, Voss WD and McFarlane WR. Service use among patients with schizophrenia in psychoeducational multiplefamily group treatment. Psychiatr Serv. 2002; 53:749-54. | Article | PubMed

Citation:

Banerjee AG and Retamero C. Expressed emotion - a determinant of relapse in schizophrenia: a case report and literature review. J Psychiatry Brain Funct. 2014; 1:4. http://dx.doi.org/10.7243/2055-3447-1-4 